\title{
Parental occupational paint exposure and risk of childhood leukemia in the offspring: Findings from the Childhood Leukemia International Consortium
}

\author{
Helen D Bailey ${ }^{1}$, Lin Fritschi ${ }^{2}$, Catherine Metayer ${ }^{3}$, Claire Infante-Rivard ${ }^{4}$, Corrado \\ Magnani $^{5}$, Eleni Petridou ${ }^{6}$, Eve Roman ${ }^{7}$, Logan G Spector ${ }^{8}$, Peter Kaatsch ${ }^{9}$, Jacqueline \\ Clavel $^{10}$, Elizabeth Milne ${ }^{11}$, John D Dockerty ${ }^{12}$, Deborah C Glass ${ }^{13}$, Tracy Lightfoot ${ }^{7}$, Lucia \\ Miligi $^{14}$, Jérémie Rudant ${ }^{10}$, Margarita Baka ${ }^{15}$, Roberto Rondelli ${ }^{16}$, Alicia Amigou ${ }^{10}$, Jill \\ Simpson $^{7}$, Alice Kang ${ }^{3}$, Maria Moschovi ${ }^{17}$, and Joachim Schüz ${ }^{1}$
}

\begin{abstract}
${ }^{1}$ International Agency for Research on Cancer (IARC), Section of Environment and Radiation, Lyon, France ${ }^{2}$ Curtin University, School of Public Health, Perth, Australia ${ }^{3}$ University of California, Berkeley, School of Public Health, Berkeley, United States ${ }^{4}$ Department of Epidemiology, Biostatistics, and Occupational Health, Faculty of Medicine, McGill University, Canada ${ }^{5}$ Dipartimento di Medicina Traslazionale - Università del Piemonte Orientale, AOU Maggiore della Carità e CPO - Piemonte, Novara, Italy ${ }^{6}$ Department of Hygiene, Epidemiology and Medical Statistics, Medical School, National and Kapodistrian University of Athens, Medical School, Athens, Greece ${ }^{7}$ Department of Health Sciences, University of York, York, United Kingdom ${ }^{8}$ Division of Epidemiology Clinical Research, Department of Pediatrics and Masonic Cancer Center, University of Minnesota, Minneapolis, United States ${ }^{9}$ German Childhood Cancer Registry (GCCR) at the Institute for Medical Biostatistics, Epidemiology and Informatics, University Medical Centre, Johannes Gutenberg University Mainz, Germany ${ }^{10}$ Inserm, CESP Centre for Research in Epidemiology and Population Health, Environmental Epidemiology of Cancer Team, Université Paris-Sud, Paris, France ${ }^{11}$ Telethon Institute for Child Health Research, University of Western Australia, Perth Australia ${ }^{12}$ Dean's Department and Department of Preventive and Social Medicine, Dunedin School of Medicine, University of Otago, Dunedin, New Zealand ${ }^{13}$ Department of Epidemiology and Preventive Medicine, Monash University, Melbourne, Australia ${ }^{14}$ ISPOCancer Prevention and Research Institute, Occupational and Environmental Epidemiology Unit, Florence, Italy ${ }^{15}$ Department of Pediatric Hematology-Oncology, "Pan.\&Agl. Kyriakou" Children's Hospital, Athens, Greece ${ }^{16}$ Paediatric Haematology -Oncology, Lalla Seràgnoli, Policlinico Sant'Orsola Malpighi Bologna Italy ${ }^{17} \mathrm{Hematology-Oncology}$ Unit, First Department of Pediatrics, Athens University Medical School, "Aghia Sophia” General Children's Hospital, Athens, Greece
\end{abstract}

\section{Abstract}

\footnotetext{
Address for correspondence: Helen Bailey, Section of Environment and Radiation, International Agency for Research on Cancer, 150 cours Albert Thomas, Lyon 69372 Cedex 08, France. Telephone: [+33] (0)4 7273 8310. Fax: [+33] (0)4 72 73 8320 baileyh@fellows.iarc.fr.

Authorship: All authors are principal investigators, co-investigators or designated collaborators of participating CLIC studies

The authors declare that they have no conflict of interest.
} 
Purpose-It has been suggested that parental occupational paint exposure around the time of conception or pregnancy increases the risk of childhood leukemia in the offspring.

Methods-We obtained individual level data from 13 case-control studies participating in the Childhood Leukemia International Consortium (CLIC). Occupational data were harmonized to a compatible format. Meta-analyses of study-specific odds ratios (ORs) were undertaken, as well as pooled analyses of individual data using unconditional logistic regression.

Results-Using individual data from fathers of 8,185 cases and 14,210 controls, the pooled OR for paternal exposure around conception and risk of acute lymphoblastic leukaemia (ALL) was 0.93 (95\% confidence interval (CI) $0.76,1.14$ ). Analysis of data from 8,156 ALL case mothers and 14,568 control mothers produced a pooled OR of $0.81(95 \%$ CI $0.39,1.68)$ for exposure during pregnancy. For acute myeloid leukaemia (AML), the pooled ORs for paternal and maternal exposure were $0.96(95 \%$ CI $0.65,1.41)$ and $1.31(95 \%$ CI $0.38,4.47)$ respectively, based on data from 1,231 case and 11,392 control fathers and 1,329 case and 12,141 control mothers. Heterogeneity among the individual studies ranged from low to modest.

Conclusions-Null findings for paternal exposure for both ALL and AML are consistent with previous reports. Despite the large sample size, results for maternal exposure to paints in pregnancy were based on small numbers of exposed. Overall, we found no evidence that parental occupational exposure to paints increases the risk of leukemia in the offspring, but further data on home exposure are needed.

\section{Keywords}

paint; parental occupation; leukemia; childhood; pooled analysis; meta-analysis

\section{Introduction}

Little is known about the etiology of childhood leukemia and its main sub-types, acute lymphoblastic leukemia (ALL) and acute myeloid leukemia (AML) but it is likely that they are attributable to a mixture of both genetic and environmental factors [1], which may vary by disease sub-type or, in the case of ALL, by immunophenotype. Some of the most common chromosomal translocations seen in ALL [2,3] and AML [4] may be of prenatal origin, suggesting a role for parental exposures. Individual studies rarely have sufficient statistical power to investigate potential risk factors by sub-type, especially for uncommon exposures. To overcome this problem, we pooled data from studies in the Childhood Leukemia International Consortium (CLIC), a multi-national collaboration of case-control studies of childhood leukemia [5]. The focus of these analyses was parental occupational exposures to paints.

It has been suggested that parental occupational paint exposure around the time of conception or pregnancy increases the risk of childhood leukemia in the offspring. Some previous studies have reported that maternal occupational exposure to paints before and during pregnancy increased the risk of ALL [6,7], and AML [8]. This last study also reported an increased risk of AML among children of fathers with 'Painter' as his job title, but not using self assessment of exposure [8]. However, other studies have found no association between paternal exposure and ALL [6,7,9-11] or AML [9]. Painting of the 
home has also been associated with ALL, with some evidence of a trend of increase in risk with higher levels of exposure [12,13]. A working group of the Monograph program of the International Agency for Cancer (IARC) on the evaluation of carcinogenic risks to humans concluded in 2010 that there was 'limited evidence that paint exposure is related to childhood leukemia', based mainly on reports of maternal exposure [14]. Paint is a generic name for a diverse range of products which can contain a large number of individual chemical compounds such as solvents, resins, binders, extenders and pigments, and some of these individual compounds have been classified as human carcinogens or probable or possible human carcinogens such as ethyl acrylate, titanium dioxide and other pigments [15].

The aim of our analyses was to investigate whether parental occupational paint exposure in the prenatal period increased the risk of ALL or AML in the offspring. We also aimed to investigate whether the relationship varied by immunophenotype of ALL. We used pooled data from 13 studies. While three of these studies have previously published findings specifically in relation to occupational paint exposure $[6,10,11]$, the majority have not.

\section{Methods}

For these analyses, we used the 13 CLIC studies that had relevant data available at the time of writing (2012); this included 12 studies with ALL cases and 10 with AML cases, conducted in North America, Europe and Australasia over a 30 year period (Table 1). Original data were requested from each of the 13 participating studies. A summary of study design and participant details, including inclusion criteria, has already been published [5]. All studies were approved by the relevant institutional or regional ethical committees. Cases of childhood leukemia other than ALL or AML were not included in these analyses.

Controls from studies with both ALL and AML cases were included in the analyses of both types of leukemia. Most studies recruited children under the age of 15 years, except the Italian SETIL study that included children up to the age of 10 years and the US Children's Oncology Group (COG)-E14 study of AML that included children up to the age of 18 years.

\section{Original occupational exposure data}

The time periods of interest were the year before conception for fathers and during the pregnancy for the mother. However, the studies had data for differing periods around conception or only during pregnancy in some studies (Table 1). In four studies, data for jobs in the time periods were extracted from the provided work history. The French Escale study had paternal exposure data for 'during pregnancy' only, so we used this as a proxy for exposure before conception. The New Zealand study asked mothers about any paint exposures at home or work during pregnancy, without separating out work specifically; thus New Zealand has been left out of the analysis of mother's specific work exposures.

Occupational data were provided in three main formats (Table 1): 1) Nine studies (France: Adele and Escale; Greece: NARECHEM 1993-1994 and 1996-2011; Germany: GCCR; Italy: SETIL; UK: UKCCS; US: NCCLS; COG-E15) provided jobs coded using an occupational coding system, which needed to be assigned paint exposure; 2) Three studies 
provided data in which the jobs in the relevant time periods had already been assessed for paint exposure and exposure assigned (Australia, Canada and New Zealand); and 3) One study provided detailed paint questionnaire data which needed to be collated to a single exposure variable (US: COG-E14).

\section{Development of a Job Exposure Matrix (JEM)}

A JEM was developed using the assessments from two of the studies from Australia [11]and Quebec, Canada [16], which had used the expert assessment method to assess occupational paint exposure [17]. In this method a full job history is taken, and job specific questionnaires are asked for each job (for example a cabinet maker would be asked the 'Carpenter' questions while a auto spray painter would be asked the 'Panel Beater' questions). The answers to these questions are reviewed on an individual level by experts who determine whether the person was likely to be exposed in that job. For each job title in the International Standard Classifications of Occupation (ISCO) 2008 (08) [18] we determined what proportion of the jobs in the Australian data were assessed as being exposed to paints. All job codes were then assigned to a category relating to the certainty of paint exposure as follows: 1) Job codes where $70 \%$ or more people (males and females combined) with the ISCO-08 code had been assessed as exposed to paint ('High likelihood of paint exposure'); 2) Job codes where $25 \%$ to $<70 \%$ were assessed as exposed ('Moderate likelihood of exposure'); 3) Job codes where 5\% to $<25 \%$ were exposed ('Limited likelihood of exposure'); and 4) Job codes where less than 5\% were exposed ('No or minimal likelihood of paint exposure' (Reference Group)). ISCO-08 jobs codes that were rare or not used in the Australian dataset were identified and these were assigned an exposure category by an occupational epidemiologist from within our team (LF). Modifications to the exposure categories were made after doing similar comparisons of expert assessment and job codings [19] from the Canadian study [16]. The final exposure codes in the ICSO-2008 JEM were then assigned to equivalent ISCO88 codes and hence to jobs in the other occupational classification systems using conversion tools (Table 1) [20-24]. In the case of 'many to one' or 'one to many' matches to job codes across systems, a judgment was made of the exposure category that best fitted the original job code description. A full list of the job codes which were categorized as highly likely to be occupationally exposed is shown in Supplementary Table 1.

\section{Harmonisation of occupational data from other studies}

Among the three studies where paint exposure had already been assigned, New Zealand had assigned paint exposure simply as exposed or non exposed as derived from more detailed data. In order to pool with the studies for which we used the JEM, we coded exposed subjects as having 'High likelihood of paint exposure'. In the Australian study [11], we coded those with 'probable high or medium exposure' as having 'High likelihood of paint exposure', and 'probable low exposure and possible low/medium/high exposure' as having 'Moderate likelihood of exposure' (Table 1). In the Canadian study [16], we coded those with 'some exposure' as having 'Moderate likelihood of exposure', and those with 'greater exposure' as having 'High likelihood of paint exposure' (Table 1). 
The US COG-E14 study had collected detailed data about exposure to spray paints, other paints and lacquers, and total contact time with paints in the air or on the skin or clothing which were categorized into the same four levels of exposure as the JEM, based on standard rules.

\section{Statistical analyses}

Two distinct analytic approaches were taken. Firstly, study specific odds ratios (ORs) of ALL and AML and exposure to paints were estimated and included in meta-analyses, in order to explore heterogeneity between studies. Secondly, as the main approach, individual data were pooled in a single dataset and the pooled ORs estimated. Because we did not believe that the 4-category final exposure measure was an accurate measure of dose of occupational exposure, the only ORs presented in the main tables are the ORs between Exposure Category 1 ('High likelihood of paint exposure') to the Reference Category 4 ('No or minimal likelihood of paint exposure') for both the study specific and pooled analyses. While those with other exposure categories were included in the analytical models, a 'trend across categories' was not investigated and results from 'Moderate likelihood of exposure' and 'Limited likelihood of exposure' categories are only shown in Supplementary Table 2. All analyses were done for ALL and AML separately.

\section{Estimation and meta-analyses of study-specific ORs}

Unconditional logistic regression (SAS version 9.2, SAS Institute Inc, Cary, NC, USA) was used to estimate study-specific ORs and 95 percent confidence intervals (95\% CIs) for occupational paint exposures for mothers during pregnancy and for fathers before conception. All models included child's age and sex and additional study-specific matching variables where applicable. Unconditional logistic regression adjusting for the original matching variables in originally individually-matched studies (all studies except Australia, France: Adele and Escale) was used to increase statistical power by optimizing the number of available cases and controls [25]. By using this method, we were able to include all subjects with complete data, even if their matched pair was missing data. Four of the individual studies had already used this method in their original analyses.[26-29] The following variables were considered a priori to be potential confounders or independently competing exposures: birth order, ethnicity, maternal age and education (for maternal analyses); and paternal age and education (for paternal analyses) and were assessed individually for inclusion in the models. Maternal and paternal educations were the only common socio-economic level indicators that were available in all studies. Factors that were independently associated with both the exposure and outcome were retained in the final models. The study-specific ORs were combined in a meta-analysis in Stata version 11.2 (StataCorp LP, College Station Texas, USA, 2009), using the random effects model (to acknowledge the between study heterogeneity [30] relating to issues such as study designs, occupational assessment methods, and changes in paint composition over time). Summary ORs, 95\% CIs, $I^{2}$ statistics (a measure of the variation across studies that is not due to chance) [31] and forest plots were produced. Studies without any cases or controls in the 'High likelihood of paint exposure' were not included in the meta-analyses (see Supplementary Tables 3 and 4 for details of which studies were included in each of the meta-analyses). 


\section{Pooled analyses}

Unconditional logistic regression (SAS version 9.2, SAS Institute Inc, Cary, NC, USA) was also used to estimate pooled ORs and 95\% CIs for occupational paint exposures in mothers during pregnancy and for fathers before conception. All models included the child's age, sex, and year of birth (grouped into five approximately equal time periods) and a variable denoting the study of origin. The following variables were tested to determine whether they were independently associated with both the exposure and outcome where the data were available: birth order; birth weight; parent's age and education (secondary education not completed, completed secondary education, and tertiary education); and ethnicity (Caucasian, European or White versus the rest) and study-specific matching variables (by allocating all the other studies the same dummy value for each variable). Of these, the following variables were retained: maternal age and education for maternal exposure and the risk of ALL; maternal education for maternal exposure and the risk of AML; and paternal education for all analyses of paternal exposures. Where possible, analyses were stratified by ALL immunophenotypes, by sex and type of occupational assessment. Results were estimated for children aged less than 5 years at diagnosis or older, to explore whether parental exposure before birth was more relevant in younger children. Finally, as there had been changes to the maximum levels of volatile organic compounds allowed in paints in the mid 1990's [32,33], results were also estimated for children born before 1996 and those born later. As children with Down syndrome have higher rates of leukemia than other children, analyses were repeated excluding these children.

The two studies with expert assessment (Australia and Canada), which only had ALL cases had both classed exposure as a two level variable, albeit using different definitions based on likelihood, level, and frequency (for one of them) of exposure. Using these data as a crude indicator of exposure dose, we also investigated a trend relationship.

\section{Sensitivity analyses}

We also created two variables to test the sensitivity of the analyses to the choice of the definition of the exposed group by using lower cut-off levels for the 'High likelihood of paint exposure' categories of the JEM for studies which had job codes. For the first sensitivity analyses we combined the first and second categories in the original JEM (that is, all jobs codes where $25 \%$ or more people were estimated to be exposed) and for the second, we used a cut off of $35 \%$ or more (which mainly included jobs related to construction, seafaring and fishing). Using these exposure category variables, we would have missed less people who were truly exposed to paint, but would have also misclassified more truly unexposed as exposed. For the studies which did not use job codes, we used the same categories as in the original variable.

\section{Results}

Data were obtained from a total of 13 studies, 12 studies for 8,835 ALL cases and from 10 studies for 1,357 AML cases (Table 2). There were 15,486 controls from studies with ALL cases and 12,443 from those with AML cases. Maternal and paternal occupational data were available for over $90 \%$ of ALL and AML cases and controls (Table 2). These figures reflect 
data missing from the original studies; for example, most studies had fewer fathers participating than mothers, and sometimes occupational histories were incomplete. Demographic characteristics of the total sample and the individual studies are shown in Supplementary Table 5.

\section{Meta-analyses of study-specific ORs}

While 12 studies with 8185 cases and 14,210 controls were included in the analysis of paternal exposure around conception and risk of ALL, only four studies with 3,306 cases and 4,356 controls were included in the meta-analysis of maternal occupational paint exposure and risk of ALL in the offspring, as the remaining studies had no cases or controls in the High likelihood of paint exposure (Supplementary Table 3). The summary ORs for paternal exposure and the risk of ALL in the offspring were 0.94 (95\% CI 0.76, 1.15) (Figure 1) and for maternal exposure $0.79(95 \%$ CI $0.36,1.71)$ with little evidence of heterogeneity among the ORs (Figure 2). When individual studies were omitted in turn from the meta-analyses, the summary estimate changed by about $5 \%$ and $18 \%$ (OR scale) for the paternal and maternal meta-analyses respectively.

Seven studies with 1,160 cases and 9,945 controls were included in the AML paternal metaanalyses (Supplementary Table 4). The summary OR for paternal occupational paint exposure and the risk of AML in the offspring was 1.09 (95\% CI 0.73, 1.63) with little or low heterogeneity among the ORs (Figure 1). When individual studies were removed one by one, the summary estimates changed by up to $14 \%$. As only one AML study had any case mothers in the 'High likelihood of paint exposure' category, no meta-analysis was performed.

\section{Pooled analyses of individual data}

The analyses for ALL included 8,185 case fathers and 14,210 control fathers from 12 studies, and 8,156 case mothers and 14,568 control mothers from 11 studies. The OR for paternal occupational paint exposure and the risk of ALL was 0.93 (95\% CI 0.76,1.14) (Table 3). There was little difference in the OR when the analyses were done by immunophenotype or when stratified by child's sex, age at diagnosis, year of birth or type of occupational assessment (Table 3), but the estimates lacked precision. When the analyses were restricted to the two studies which used expert assessment with two levels of exposure, no evidence of a trend relationship was found in relation to paternal exposure and the risk of ALL ( $\mathrm{p}$ trend 0.37, results not otherwise shown). The pooled OR for maternal occupational paint exposure during pregnancy and the risk of ALL was 0.81 (95\% CI 0.39, 1.68) (data not otherwise shown). There were only 13 case mothers $(0.16 \%)$ and 20 control mothers $(0.14 \%)$ in the 'High likelihood of paint exposure' category so the only sub group analysis was the investigation of a trend relationship using the two studies with a two level exposure variable, based on expert assessment. The small numbers in the highest exposure category (6 cases and 10 controls) prevented any meaningful assessment of a trend relationship. The ORs for the two levels of exposure were 0.77 (95\% CI $0.27,2.16)$ for the highest level and $1.61(95 \%$ CI $1.11,2.32)$ for the lower category but one study contributed nearly all the subjects to these analyses. 
The analyses for AML included 1,231 case fathers and 11,392 control fathers from ten studies and 1,309 case mothers and 11,859 control mothers from nine studies. The OR for paternal exposure around conception was 0.96 (95\% CI 0.65, 1.41), with little difference seen when stratified by sex, age at diagnosis, year of birth or type of occupational assessment (Table 3). The OR for maternal occupational paint exposure during pregnancy and risk of AML was 1.31 (95\% CI 0.38, 4.47), with five cases $(0.4 \%)$, who were all from US COG E-14 and ten control mothers $(0.1 \%)$ in the 'High likelihood of paint exposure' category (data not otherwise shown). Thus, no sub-group analyses were performed.

When all the analyses for ALL and AML were repeated excluding children with Down syndrome (103 ALL cases and six controls, 89 AML cases and four controls), there was little change in the results and there was also little difference when the analyses were adjusted for the exposure level of the other parent (data not shown).

Influence analyses for paternal exposure were performed by leaving out individual studies in turn and then two studies in turn. Leaving out studies made little difference to the results (data not shown).

When we repeated the analyses using the two sensitivity variables with different definitions of 'High likelihood of paint exposure', the proportion of cases and controls in the estimates were in line with the original findings for both of the sensitivity variables (data not shown). However, the proportion of women in the 'High likelihood of paint exposure' categories remained low for both variables ( $0.6 \%$ and $0.4 \%$ of control mothers respectively).

\section{Discussion}

We found no evidence of any association between paternal or maternal occupational exposure to paints and ALL or AML in the offspring. Estimates for maternal exposure lacked precision because there were so few women in the high exposure group.

Our null findings in relation to paternal exposure to paint and ALL are similar to previously published literature [7,9]. Not surprisingly, they are also consistent with the published findings of three of the CLIC studies which contributed $28 \%$ of cases to the current pooled analyses $[6,10,11]$, despite the different methods of occupational assessment used in the initial reports $[6,10]$. The null findings for AML are also similar to those of a large UK study with 2,367 cases which assigned exposure based on job title [9], but not with those of a study from the US which assigned exposure based on job titles, but which included few exposed men (seven cases and one control) [8].

Despite having over 8,000 ALL cases, 1,000 AML cases and 14,000 controls, we had low statistical power to investigate maternal exposure as so few women $(<0.5 \%)$ were assigned to the 'High likelihood of paint exposure' category. Because of the format of the original data, we could only investigate likelihood of exposure, not level of exposure. Using the studies with expert assessment, there was an increased risk of ALL following maternal paint exposure at low levels during pregnancy, but as only one of the studies contributed most of the subjects to this analysis, these findings are hard to interpret. The IARC Monograph which concluded that there was 'limited evidence that paint exposure is related to childhood 
leukemia' [14], had reviewed the findings of four reports (three of ALL) related to maternal occupational exposure to paints $[6-8,34]$ as well as the findings in relation to home exposures $[12,13,35]$. The two studies that found an increased risk of ALL with maternal occupational exposure to paints during pregnancy [6,7] were the German study and US COG E-15 that are part of the current CLIC pooled analyses; however, both these original studies used different occupational assessment from those used in the current analyses. Our current analyses using a JEM which identified parents highly likely to have been exposed found much lower prevalence of exposure (combined study total of $0.1 \%$ of cases and $0.1 \%$ of controls) than in the original studies. The investigators in the German study [6] concluded that their positive finding, based on self assessment, was related to differential bias as a higher proportion of case mothers than control mothers reported exposures that seemed implausible when the job codes were examined. In addition, the German translation of the word 'colorants' which was included in the definition of 'paints' was similar to the translation for hair colorants, so women who were hairdressers reported that they had been exposed [36]. The third ALL study [34] evaluated for the IARC Monograph [14] found an increased risk of ALL with maternal occupational exposure to the broad category of 'chemicals' which, in addition to paints, included petroleum products and other unspecified chemicals, with $4.8 \%$ of case and $2.2 \%$ of control mothers classified as exposed. Thus the different finding could be related to exposures other than paints.

The only previous study which reported an increased risk with AML [8] also used selfreported paint exposures to assign exposure with $15 \%$ of case mothers and $9 \%$ of control mothers reporting exposure, thus the concerns about recall bias could also apply.

Recruiting control subjects who are representative of the source population from which the cases are drawn is one of the greatest challenges in case-control studies[37]. Each of the original studies had chosen what was thought to be the most appropriate source and method to recruit such controls in their source population at the time the study was conducted (Table 1). While most had used individually matched controls, others had used frequency matching and the ratio of cases to controls varied. In order to pool the data, we decided to break the original matching, but we adjusted for the main matching factors (age and sex) in the analyses and as well tested the relevance of other individual study matching factors such as geographical region. Breaking the individual matching allowed us to use all available cases and controls with still controlling for possible confounding. This approach had already been used in the analyses of some of the original studies we pooled and shown to keep the validity of the study findings.

The major strength of this current investigation was the large sample size and access to the original data to harmonize exposure assessment and categories. Despite this, the analyses of paternal exposure by sub-type of leukemia lacked statistical power.

Another major strength was that all studies collected information about the jobs held, rather than directly about exposure, a method which, as we have noted above, is more prone to recall bias. The studies that included more probing questions about paint use, asked these in a structured manner only after the job information had been obtained. In addition, paint exposure was assigned blinded to case control status of subjects, whether this was done in 
the original study or during the current investigation. However, there were methodological challenges because of the different forms of occupational exposure data provided by different CLIC studies. In order to harmonize the data, a crude measure of exposure was developed. For most studies, we had only job title information coded in different formats. Most of the job titles that we included in the 'High likelihood of paint exposure' category had the words 'paint or 'painter' in the title, thus we can assume they were exposed to paint. However, we may have missed other individuals with high levels of paint exposure who had other job titles. The proportion of controls categorized in the 'High likelihood of paint exposure' was generally lower in studies where exposure was based on job title than in the four studies which assigned exposure using more discriminatory methods. When we lowered the cut off for 'High likelihood of paint exposure', our findings were unchanged, but as we expect to have increased the amount of misclassification in the exposure variable (in particular more false positives), caution is warranted as the increased level of non differential measurement error may have biased these findings towards the null.

Despite these limitations, the estimates obtained for paternal exposure and both ALL and AML using studies that had used coded job titles were similar to the four studies that used other methods of occupational assessment. It is unlikely that all people would have the same level of exposure in all industries and that exposures would have been similar across all the study populations (North America, Europe and Australasia) and over time (30 years). The types of paints used would have varied by industry and the composition of paints would have changed over time. For example, in the mid 1990's, changes to government legislation resulted in a reduction in the volatile organic compounds allowed in paints in many countries such as the United States [32], and United Kingdom [33]. However our findings were similar for fathers of children born before 1996 and those born in or after 1996.

The focus of our study was parental occupational exposure and not exposure in the home. In the home, paint exposure can occur in two ways. Firstly, a person can be exposed by the individual using paint themselves. Secondly, they can also be exposed by spending time in an environment where paint had recently been used, such as living in a freshly painted house. While the level of exposure may be lower, the exposure can extend over a prolonged time period [38]. In addition, it may also be more common as a Danish cohort study reported that $45 \%$ of pregnant women were exposed to paint fumes in the home [39].

In conclusion, we found no association between parental occupational exposure to paints and the risk of childhood leukemia, including among disease subgroups for fathers. Our null findings for maternal exposure were based on small numbers, but as there was some evidence of an increased risk with low levels of exposure in one of the studies, further investigations using detailed occupational assessments are needed as are data on home exposures.

\section{Supplementary Material}

Refer to Web version on PubMed Central for supplementary material. 


\section{Acknowledgments}

\section{Funding}

The work reported in this paper by Helen Bailey was undertaken during the tenure of a Postdoctoral Fellowship from the International Agency for Research on Cancer, partially supported by the European Commission FP7 Marie Curie Actions, - People- Co-funding of regional, national and international programmes (COFUND). The CLIC administration, annual meetings, and pooled analyses are partially supported by the National Cancer Institute, NCI, USA (grant R03CA132172), National Institute of Environmental Health Sciences, NIEHS, USA (grants P01 ES018172 and R13 ES021145-01), the Environmental Protection Agency, EPA, USEPA, USA (grant RD83451101), and the Children with Cancer, CwC, UK (Award No. 2010/097).

Aus-ALL was supported by the Australian National Health and Medical Research Council (Grant ID 254539).

The Canadian study was funded by The National Cancer Institute of Canada; Grant numbers: \#014113, \#010735CERN \#RFA0405; The Medical Research Council of Canada; Grant number: MOP 37951; The Fonds de la recherche en santé du Québec; Grant number: \#981141; The Bureau of Chronic Disease Epidemiology, Canada; Health and Welfare Canada; The Leukemia Research Fund of Canada; and the National Health and Research Development Program, Ottawa.

ADELE Grant sponsors: INSERM, the French Ministère de l'Environnement, the Association pour la Recherche contre le Cancer, the Fondation de France, the Fondation Jeanne Liot, the Fondation Weisbrem-Berenson, the Ligue Contre le Cancer du Val de Marne, the Ligue Nationale Contre le Cancer.

ESCALE Grant sponsors: INSERM, the Fondation de France, the Association pour la Recherche sur le Cancer (ARC), the Agence Française de Sécurité Sanitaire des Produits de Santé (AFSSAPS), the AgenceFrançaise de Sécurité Sanitaire de l'Environnement et du Travail (AFSSET), the association Cent pour sang la vie, the Institut National du Cancer (INCa), the Agence Nationale de la Recherche (ANR), the Cancéropôle Ile-de-France;

The German study (GCCR) was supported by a grant from the Federal Ministry of the Environment, Nuclear Safety and Nature Preservation.

NARECHEM, is supported in part by the National and Kapodistrian University, Athens, Greece.

The SETIL study was financially supported by research grants received by AIRC (Italian Association on Research on Cancer), MIUR (Ministry for Instruction, University and Research), Ministry of Health, Ministry of Labour, Piedmont Region.

The New Zealand Childhood Cancer Study was funded by the Health Research Council of NZ, the NZ Lottery Grants Board, the Otago Medical School (Faculty Bequest Funds), the Cancer Society of NZ, the Otago Medical Research Foundation, and the A.B. de Lautour Charitable Trust.

The Northern California Childhood Leukemia Study (NCCLS) is supported by the National Institutes of Health (NIH), USA (grants P01 ES018172, R01 ES09137, and P42-ES04705), Environmental Protection Agency (USEPA), USA (grant RD83451101), and the CHILDREN with CANCER (CwC), UK (former Children with Leukaemia) for data collection. The content is solely the responsibility of the authors and does not necessarily represent the official views of the NIH, USEPA, or the CwC.

The United Kingdom Childhood Cancer Study (UKCCS) is sponsored and administered by Leukaemia and Lymphoma Research. The researchers are independent from the funders.

COG: The E14 and E15 cohorts of the Children's Oncology Group were funded by National Institutes of Health (NIH), USA (Grants R01CA049450 (E14) and R01CA048051 (E15)) and The Children's Cancer Research Fund, Minneapolis, $\mathrm{MN}$

We would like to thank our dear colleague and friend, Patricia Buffler, who passed away before the submission of this manuscript. She was a founding member and Chair of CLIC as well as the driving force behind the NCCLS. She provided unconditional support to finding the causes of childhood leukemia, and her scientific leadership and guiding forces within CLIC will be remembered.

The Aus-ALL consortium conducted the study and the Telethon Institute for Child Health Research (TICHR), University of Western Australia, was the coordinating centre. Bruce Armstrong (Sydney School of Public Health), Elizabeth Milne (TICHR), Frank van Bockxmeer (Royal Perth Hospital), Michelle Haber (Children's Cancer Institute Australia), Rodney Scott (University of Newcastle), John Attia (University of Newcastle), Murray Norris (Children's Cancer Institute Australia), Carol Bower (TICHR), Nicholas de Klerk (TICHR), Lin Fritschi (WA 
Institute for Medical Research, WAIMR), Ursula Kees (TICHR), Margaret Miller (Edith Cowan University), Judith Thompson (WA Cancer Registry) were the research investigators, Helen Bailey (TICHR) was the project coordinator and Alison Reid (WAIMR) performed the occupational analyses. The clinical Investigators were: Frank Alvaro (John Hunter Hospital, Newcastle); Catherine Cole (Princess Margaret Hospital for Children, Perth); Luciano Dalla Pozza (Children's Hospital at Westmead, Sydney); John Daubenton (Royal Hobart Hospital, Hobart); Peter Downie (Monash Medical Centre, Melbourne); Liane Lockwood, (Royal Children's Hospital, Brisbane); Maria Kirby (Women's and Children's Hospital, Adelaide); Glenn Marshall (Sydney Children's Hospital, Sydney); Elizabeth Smibert (Royal Children's Hospital, Melbourne); Ram Suppiah, (previously Mater Children's Hospital, Brisbane).

GCCR: The German study was conducted by the nationwide German Childhood Cancer Registry (GCCR) at the Institute of Medical Biostatistics, Epidemiology and Informatics at the Johannes Gutenberg-University Mainz; researchers involved were Drs Jörg Michaelis (head), Peter Kaatsch, Uwe Kaletsch, Rolf Meinert, Anke Miesner and Joachim Schüz.

NARECHEM Greek Pediatric Hematology Oncology Clinicians: Margarita Baka MD: Department of Pediatric Hematology -Oncology, "Pan.\&Agl. Kyriakou" Children's Hospital, Athens, Greece, Thivon \& Levadeias, Goudi; Maria Moschovi MD: Hematology-Oncology Unit, First Department of Pediatrics, Athens University Medical School, “Aghia Sophia” General Children's Hospital, Athens, Greece, Thivon \& Papadiamantopoulou, Goudi, 11527 Athens, Greece; Sophia Polychronopoulou MD: Department of Pediatric Hematology-Oncology, "Aghia Sophia" General Children's Hospital, Athens, Greece, Thivon \& Papadiamantopoulou, Goudi, 11527 Athens, Greece; Emmanuel Hatzipantelis MD, PhD: Pediatric Hematology Oncology Unit, 2nd Pediatric Department of Aristotle University, AHEPA General Hospital, Thessaloniki, Greece, 1 St. Kyriakidi, 54636 Thessaloniki, Greece; Ioanna Fragandrea MD: Pediatric Oncology Department, Hippokration Hospital, Thessaloniki, Greece; Eftychia Stiakaki MD: Department of Pediatric Hematology-Oncology, University Hospital of Heraklion, Heraklion, Greece; Nick Dessypris, MSc, PhD and Evanthia Bouka, MPH: Department of Hygiene, Epidemiology and Medical Statistics, Athens University Medical School, 11527 Athens, Greece; Ioannis Matsoukis MD: Department of Hygiene, Epidemiology and Medical Statistics, Athens University Medical School, 11527 Athens, Greece.

The SETIL (Italian Multicentric Epidemiological Study on Risk Factors of Childhood Leukaemia, Non Hodgkin Lymphoma and Neuroblastoma) Working Group: Corrado Magnani and Alessandra Ranucci (Cancer Epidemiology Unit, CPO Piedmont Novara); Lucia Miligi, Alessandra Benvenuti, Patrizia Legittimo and Angela Veraldi (Occupational and Environmental Unit, ISPO, Firenze); Antonio Acquaviva (AOU Siena); Maurizio Aricò, Alma Lippi and Gabriella Bernini (AOU Meyer, Firenze); Giorgio Assennato (ARPA, Bari); Stefania Varotto and Paola Zambon (Università di Padova); Pierfranco Biddau and Roberto Targhetta (Ospedale Microcitemico, Cagliari); Luigi Bisanti and Giuseppe Sampietro (ASL di Milano); Francesco Bochicchio, Susanna Lagorio, Cristina Nuccetelli, Alessandro Polichetti and Serena Risica, (ISS, Roma); Santina Cannizzaro and Lorenzo Gafà (LILT, Ragusa); Egidio Celentano (ARSan, Napoli); Pierluigi Cocco (Università di Cagliari); Marina Cuttini (IRCCS Burlo Garofolo, Trieste); Francesco Forastiere, Ursula Kirchmayer and Paola Michelozzi (Dipartimento Epidemiologia Regione Lazio, Roma); Erni Guarino (INT Napoli); Riccardo Haupt (Istituto Giannina Gaslini, Genova); Franco Locatelli (Università di Pavia and AO Bambin Gesù, Roma); Lia Lidia Luzzatto (ASL 1, Torino); Giuseppe Masera (Università Milano Bicocca, Monza); Pia Massaglia (Università di Torino); Stefano Mattioli and Andrea Pession (Università di Bologna); Domenico Franco Merlo and Vittorio Bocchini (IST, Genova); Liliana Minelli and Manuela Chiavarini (Università degli Studi di Perugia); Margherita Nardi (AOU Pisa); Paola Mosciatti and Franco Pannelli (Università di Camerino); Vincenzo Poggi (AORN Santobono - Pausilipon, Napoli); Alessandro Pulsoni (Sapienza University, Roma); Carmelo Rizzari (AO San Gerardo, Monza); Roberto Rondelli (Policlinico S. Orsola, Bologna); Gino Schilirò (Università di Catania); Alberto Salvan (IASI-CNR, Roma); Maria Valeria Torregrossa and Rosaria Maria Valenti, (Università degli Studi di Palermo); Alessandra Greco, Gian Luca DeSalvo and Daniele Monetti (IOV-IRCCS, Padova); Claudia Galassi (San Giovanni Battista Hospital, Torino); Veronica Casotto (IRCCS Burlo Garofolo, Trieste); Gigliola de Nichilo (ASL BT, SPRESAL Barletta); Alberto Cappelli, (Accademia dei Georgofili, Florence).

The New Zealand Childhood Cancer Study was co-ordinated at the University of Otago, where the study team included JD Dockerty, GP Herbison (who helped prepare data for this pooled analysis), DCG Skegg and JM Elwood. The names of the interviewers, secretaries, research assistants, clinicians, pathologists and cancer registry staff who contributed are listed in earlier publications from the NZ study.

The UKCCS was conducted by 12 teams of investigators (ten clinical and epidemiological and two biological) based in university departments, research institutes, and the National Health Service in Scotland. Its work is coordinated by a management committee. Further information can be found on the web-site www.ukccs.org.

COG: The E14 and E15 cohorts of the Children's Oncology Group was identified by CCG (Children's Cancer Group) principle and affiliate member institutions. Further information can be found on the web-site: http:// www.curesearch.org/. 
The NCCLS thanks the families for their participation and the clinical investigators at the following collaborating hospitals for help in recruiting patients: University of California Davis Medical Center (Dr. J. Ducore), University of California San Francisco (Drs. M. Loh and K. Matthay), Children's Hospital of Central California (Dr. V. Crouse), Lucile Packard Children's Hospital (Dr. G. Dahl), Children's Hospital Oakland (Dr. J. Feusner), Kaiser Permanente Roseville (former Sacramento; Drs. K. Jolly and V. Kiley), Kaiser Permanente Santa Clara (Drs. C. Russo, A. Wong, and D. Taggar), Kaiser Permanente San Francisco (Dr. K. Leung), and Kaiser Permanente Oakland (Drs. D. Kronish and S. Month). Finally, the NCCLS thanks the entire study staff and former University of California, Berkeley Survey Research Center for their effort and dedication.

The French authors would like to thank all of the Société Française de lutte contre les Cancers de l'Enfant et de l'Adolescent (SFCE) principal investigators: André Baruchel (Hôpital Saint-Louis/Hôpital Robert Debré, Paris), Claire Berger (Centre Hospitalier Universitaire, Saint-Etienne), Christophe Bergeron (Centre Léon Bérard, Lyon), Jean-Louis Bernard (Hôpital La Timone, Marseille), Yves Bertrand (Hôpital Debrousse, Lyon), Pierre Bordigoni (Centre Hospitalier Universitaire, Nancy), Patrick Boutard (Centre Hospitalier Régional Universitaire, Caen), Gérard Couillault (Hôpital d'Enfants, Dijon), Christophe Piguet (Centre Hospitalier Régional Universitaire, Limoges), Anne-Sophie Defachelles (Centre Oscar Lambret, Lille), François Demeocq (Hôpital Hôtel-Dieu, Clermont-Ferrand), Alain Fischer (Hôpital des Enfants Malades, Paris), Virginie Gandemer (Centre Hospitalier Universitaire - Hôpital Sud, Rennes), Dominique Valteau-Couanet (Institut Gustave Roussy, Villejuif), Jean-Pierre Lamagnere (Centre Gatien de Clocheville, Tours), Françoise Lapierre (Centre Hospitalier Universitaire Jean Bernard, Poitiers), Guy Leverger (Hôpital Armand-Trousseau, Paris), Patrick Lutz (Hôpital de Hautepierre, Strasbourg), Geneviève Margueritte (Hôpital Arnaud de Villeneuve, Montpellier), Françoise Mechinaud (Hôpital Mère et Enfants, Nantes), Gérard Michel (Hôpital La Timone, Marseille), Frédéric Millot (Centre Hospitalier Universitaire Jean Bernard, Poitiers), Martine Münzer (American Memorial Hospital, Reims), Brigitte Nelken (Hôpital Jeanne de Flandre, Lille), Hélène Pacquement (Institut Curie, Paris), Brigitte Pautard (Centre Hospitalier Universitaire, Amiens), Stéphane Ducassou (Hôpital Pellegrin Tripode, Bordeaux), Alain Pierre-Kahn (Hôpital Enfants Malades, Paris), Emmanuel Plouvier (Centre Hospitalier Régional, Besançon), Xavier Rialland (Centre Hospitalier Universitaire, Angers), Alain Robert (Hôpital des Enfants, Toulouse), Hervé Rubie (Hôpital des Enfants, Toulouse), Stéphanie Haouy (Hôpital Arnaud de Villeneuve, Montpellier), Christine Soler (Fondation Lenval, Nice), and Jean-Pierre Vannier (Hôpital Charles Nicolle, Rouen).

The Canada, Québec Study was conducted in the province over a twenty year period in all university-affiliated pediatric centers hospitals designated to diagnose and treat pediatric cancers, under the direction of Claire InfanteRivard. Main support collaborators were Alexandre Cusson, Marcelle Petitclerc and Denyse Hamer. We thank all families for their generous participation

\section{Abbreviations}

ALL

AML

Aus-ALL

CI

CLIC

COG

ESCALE

GCCR

ISCO

JEM

NARECHEM

NCCLS

NEC acute lymphoblastic leukemia

acute myeloid leukemia

Australian Study of Causes of Acute Lymphoblastic Leukaemia in Children

Confidence interval

Childhood Leukemia International Consortium

Childhood Oncology Group (Children's Cancer Group)

Epidemiological Study on childhood Cancer and Leukemia

German Childhood Cancer Registry

International Standard Classification for Occupation

Job Exposure Matrix

Nationwide Registration for Childhood Haemotological Malignancies

Northern California Childhood Leukemia Study (USA)

Not else classified 
NZCCS New Zealand Childhood Cancer Study

OR Odds ratio

RDD random digit dialling

SETIL Italian Multicentric Epidemiological Study on Risk Factors for Childhood Leukaemia and Non-Hodgkin's Lymphoma

UKCCS United Kingdom Childhood Cancer Study

\section{Reference List}

1. McNally RJ, Parker L. Environmental factors and childhood acute leukemias and lymphomas. Leuk Lymphoma. 2006; 47:583-98. [PubMed: 16690516]

2. Gruhn B, Taub JW, Ge Y, et al. Prenatal origin of childhood acute lymphoblastic leukemia, association with birth weight and hyperdiploidy. Leukemia. 2008; 22:1692-7. [PubMed: 18548099]

3. Eguchi-Ishimae M, Eguchi M, Kempski H, Greaves M. NOTCH1 mutation can be an early, prenatal genetic event in T-ALL. Blood. 2008; 111:376-8. [PubMed: 17901244]

4. McHale CM, Wiemels JL, Zhang L, et al. Prenatal origin of childhood acute myeloid leukemias harboring chromosomal rearrangements $t(15 ; 17)$ and inv(16). Blood. 2003; 101:4640-1. [PubMed: 12756163]

5. Metayer C, Milne E, Clavel J, et al. The Childhood Leukemia International Consortium. Cancer Epidemiol. 2013; 37:336-47. [PubMed: 23403126]

6. Schuz J, Kaletsch U, Meinert R, Kaatsch P, Michaelis J. Risk of childhood leukemia and parental self-reported occupational exposure to chemicals, dusts, and fumes: results from pooled analyses of German population-based case-control studies. Cancer Epidemiol Biomarkers Prev. 2000; 9:835-8. [PubMed: 10952101]

7. Shu XO, Stewart P, Wen WQ, et al. Parental occupational exposure to hydrocarbons and risk of acute lymphocytic leukemia in offspring. Cancer Epidemiol Biomarkers Prev. 1999; 8:783-91. [PubMed: 10498397]

8. Buckley JD, Robison LL, Swotinsky R, et al. Occupational exposures of parents of children with acute nonlymphocytic leukemia: a report from the Childrens Cancer Study Group. Cancer Res. 1989; 49:4030-7. [PubMed: 2736544]

9. Keegan TJ, Bunch KJ, Vincent TJ, et al. Case-control study of paternal occupation and childhood leukaemia in Great Britain, 1962-2006. Br J Cancer. 2012; 107:1652-9. [PubMed: 22968649]

10. McKinney PA, Fear NT, Stockton D. Parental occupation at periconception: findings from the United Kingdom Childhood Cancer Study. Occup Environ Med. 2003; 60:901-9. [PubMed: 14634180]

11. Reid A, Glass DC, Bailey HD, et al. Parental occupational exposure to exhausts, solvents, glues and paints, and risk of childhood leukemia. Cancer Causes Control. 2011; 22:1575-85. [PubMed: 21866372]

12. Freedman DM, Stewart P, Kleinerman RA, et al. Household solvent exposures and childhood acute lymphoblastic leukemia. Am J Public Health. 2001; 91:564-7. [PubMed: 11291366]

13. Scelo G, Metayer C, Zhang L, et al. Household exposure to paint and petroleum solvents, chromosomal translocations, and the risk of childhood leukemia. Environ Health Perspect. 2009; 117:133-9. [PubMed: 19165400]

14. International Agency for Research on Cancer. Painting, Firefighting, and Shiftwork. International Agency for Research on Cancer; 2010.

15. International Agency for Research on Cancer. Part F: A Review of Human Carcinogens: Chemical Agents and Related Occupations. Lyon: International Agency for Research on Cancer; 2009. Occupational exposure as a painter. 
16. Infante-Rivard C, Siemiatycki J, Lakhani R, Nadon L. Maternal exposure to occupational solvents and childhood leukemia. Environ Health Perspect. 2005; 113:787-92. [PubMed: 15929905]

17. Siemiatycki J, Day NE, Fabry J, Cooper JA. Discovering carcinogens in the occupational environment: a novel epidemiologic approach. J Natl Cancer Inst. 1981; 66:217-25. [PubMed: 6935472]

18. International Labour Office. ISCO 08 International Standard Classification of Occupation. Vol. 1. Geneva: International Labour Office; 2012.

19. Department of Manpower and Immigration. Canadian Classification and Dictionary of Occupations 1971, Volume 1: Classifications and definitions. Ottawa, Canada: Information Canada; 1971.

20. International Labour Office. Correspondence table ISCO-08 to ISCO-88. 2013.

21. International Labour Office. ISCO-88 International Standard Classification of Occupations. Geneva: International Labour Office; 1990.

22. Federal Statistical Office Germany. Klassifikation de Berufe- Kld-92- mit der Signierung für den Mikrozenus in Verbindung mit dem Umsteigerschüssel für die Internationale Standardklassifikation der berufe zur Anwendung in der Europäischen Gemeinschaft - ISCO COM; Wiesbaden. 1992.

23. Classifications and Harmonisation Unit Office for National Statistics (UK). OOSS User Guide 1990:01.2 Mapping of Standard Occupational Classification 1990 (SOC 1990) to International Standard Classification Of Occupations European Community version (ISCO-88 Com). 1990.

24. National Crosswalk Service Center. The National Crosswalk Service Center (NCSC). 2012.

25. Brookmeyer R, Liang KY, Linet M. Matched case-control designs and overmatched analyses. Am J Epidemiol. 1986; 124:693-701. [PubMed: 3752063]

26. Smith A, Lightfoot T, Simpson J, Roman E. Birth weight, sex and childhood cancer: A report from the United Kingdom Childhood Cancer Study. Cancer Epidemiol. 2009; 33:363-7. [PubMed: 19932649]

27. Hug K, Grize L, Seidler A, Kaatsch P, Schuz J. Parental Occupational Exposure to Extremely Low Frequency Magnetic Fields and Childhood Cancer: A German Case-Control Study. Am J Epidemiol. 2010; 171:27-35. [PubMed: 19942577]

28. Dockerty JD, Skegg DCG, Elwood JM, Herbison GP, Becroft DMO, Lewis ME. Infections, vaccinations, and the risk of childhood leukaemia. Br J Cancer. 1999; 80:1483-9. [PubMed: 10424755]

29. Miligi L, Benvenuti A, Mattioli S, et al. Risk of childhood leukaemia and non-Hodgkin's lymphoma after parental occupational exposure to solvents and other agents: the SETIL Study. Occup Environ Med. 2013; 70:648-55. [PubMed: 23729503]

30. Riley RD, Higgins JP, Deeks JJ. Interpretation of random effects meta-analyses. Br Med J. 2011; 342:d549. [PubMed: 21310794]

31. Higgins JP, Thompson SG, Deeks JJ, Altman DG. Measuring inconsistency in meta-analyses. Br Med J. 2003; 327:557-60. [PubMed: 12958120]

32. Tibbetts J. Under construction: building a safer industry. Environ Health Perspect. 2002; 110:A134-A141. [PubMed: 11882489]

33. The volatile organic compounds in paints, varnishes and vehicle refinishing products regulations. United Kingdom: 2005. [Statute on Internet]. cited

34. van Steensel-Moll HA, Valkenburg HA, van Zanen GE. Childhood leukemia and parental occupation. A register-based case-control study. Am J Epidemiol. 1985; 121:216-24. [PubMed: 3860001]

35. Lowengart RA, Peters JM, Cicioni C, et al. Childhood leukemia and parents' occupational and home exposures. J Natl Cancer Inst. 1987; 79:39-46. [PubMed: 3474448]

36. Schuz J, Spector LG, Ross JA. Bias in studies of parental self-reported occupational exposure and childhood cancer. Am J Epidemiol. 2003; 158:710-6. [PubMed: 14507608]

37. Wacholder S, McLaughlin JK, Silverman DT, Mandel JS. Selection of controls in case-control Studies .1. Principles. Am J Epidemiol. 1992; 135:1019-28. [PubMed: 1595688] 
38. Raw GJ, Coward SK, Brown VM, Crump DR. Exposure to air pollutants in English homes. J Expo Anal Environ Epidemiol. 2004; 14(Suppl 1):S85-S94. [PubMed: 15118750]

39. Sorensen M, Andersen AMN, Raaschou-Nielsen O. Non-occupational exposure to paint fumes during pregnancy and fetal growth in a general population. Environ Res. 2010; 110:383-7.

[PubMed: 20219188] 


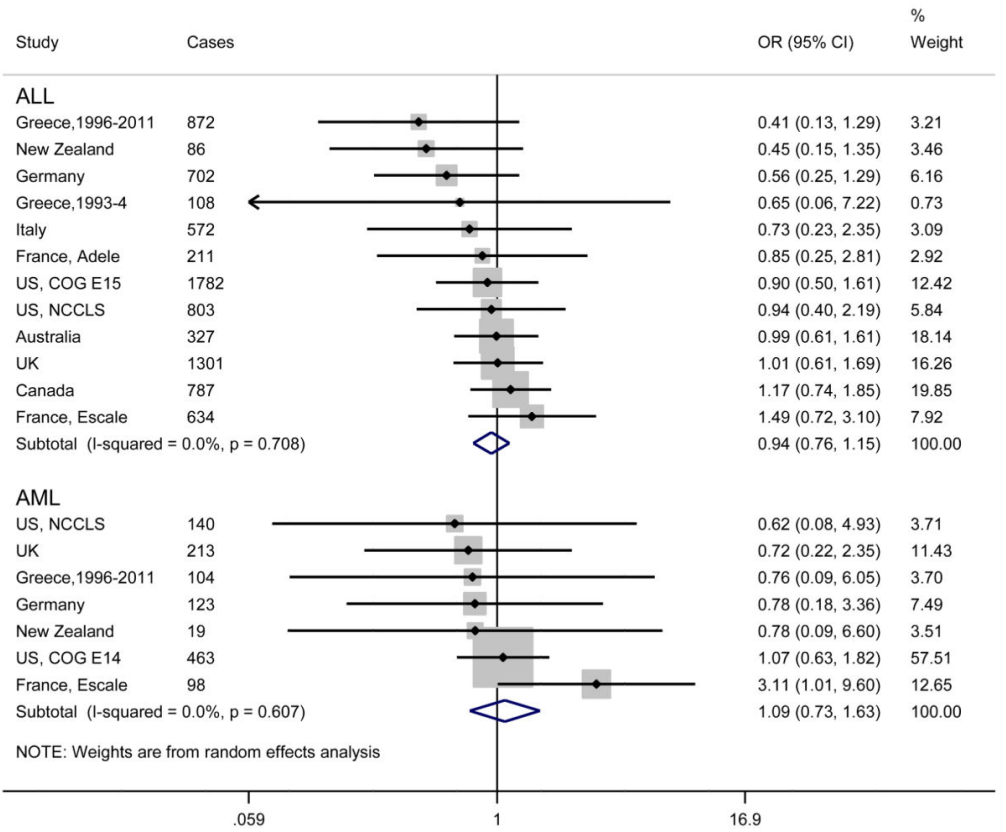

Figure 1.

Forest plot showing individual and summary odds ratios for paternal occupational paint exposure and the risk of ALL and AML in the offspring (comparing 'Highly likely to be exposed' group to 'Unlikely to be exposed' group (reference), using random effects models. 


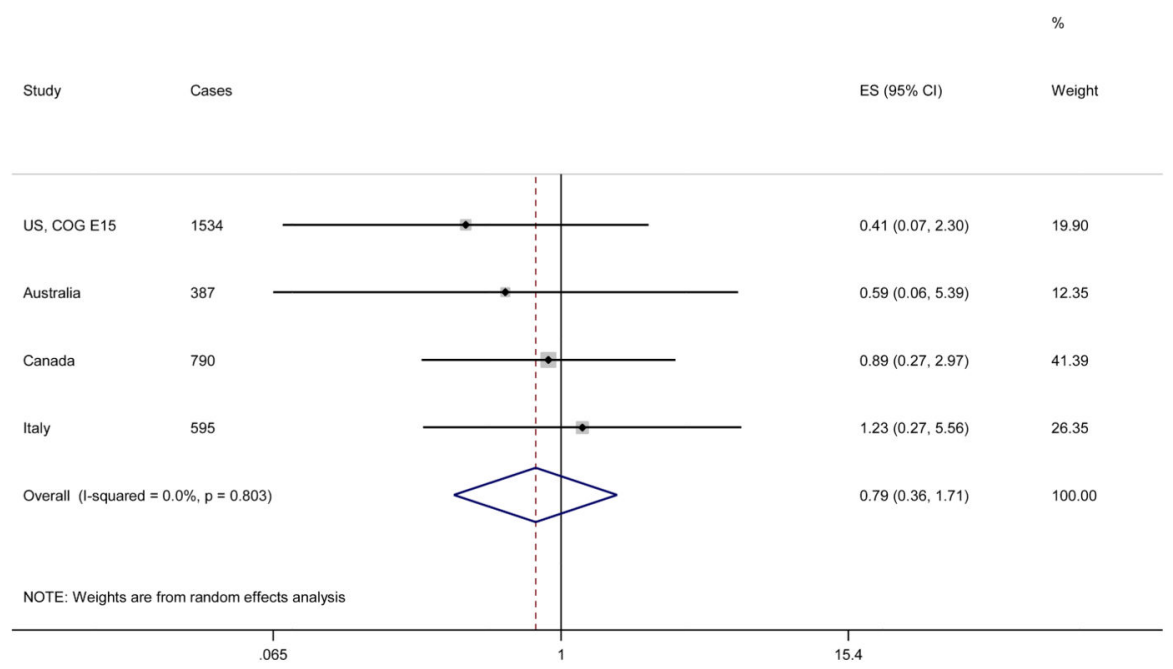

Figure 2.

Forest plot showing individual and summary odds ratios for maternal occupational paint exposure during pregnancy and the risk of ALL in the offspring (comparing 'Highly likely to be exposed' group to 'Unlikely to be exposed' group (reference), using random effects model. 


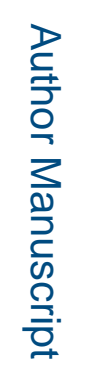

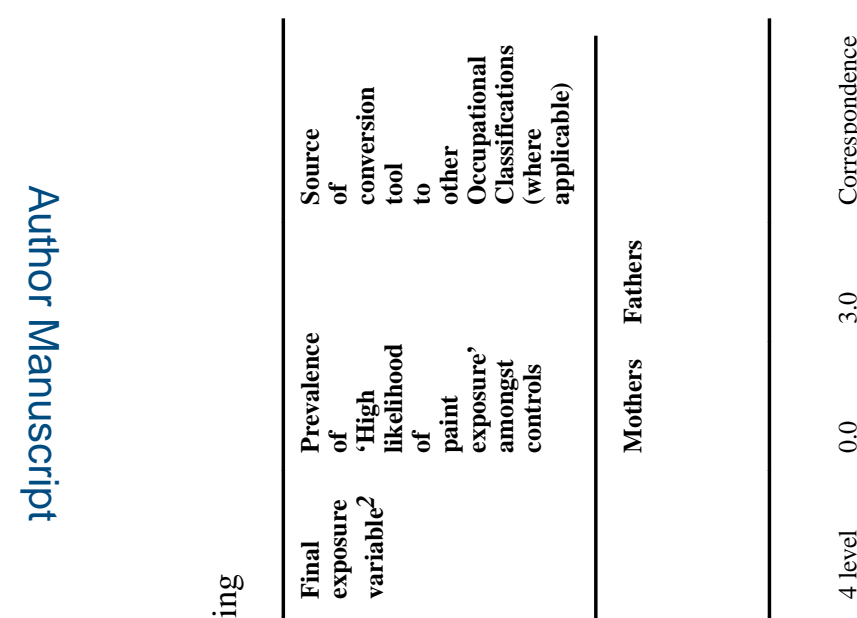

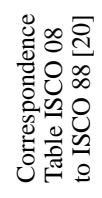

ํ.

:

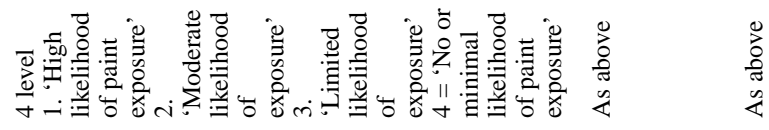



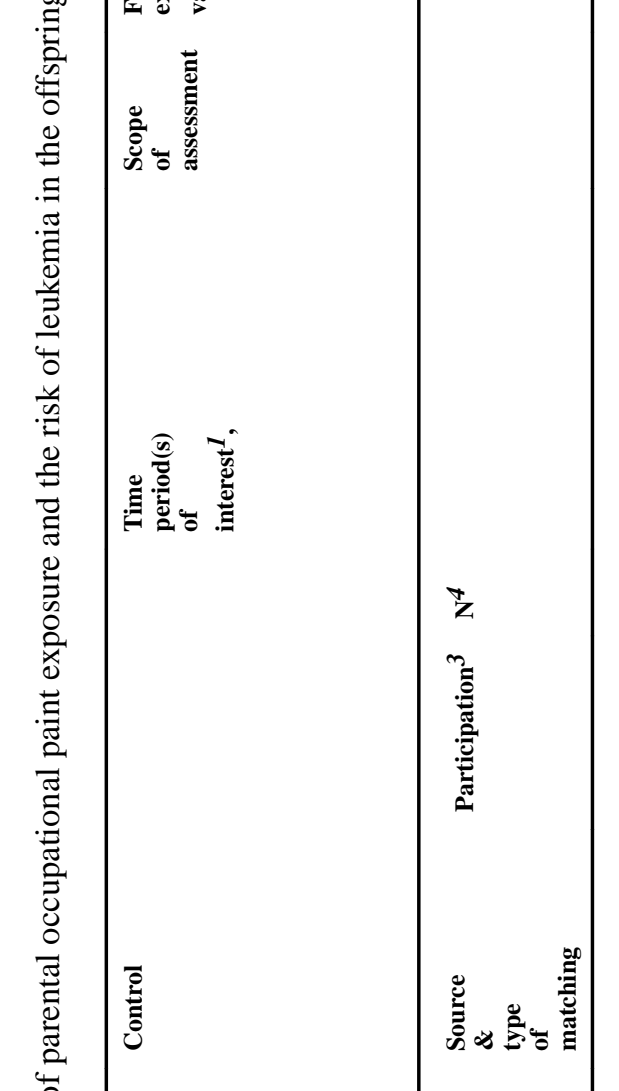

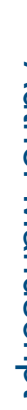

高)

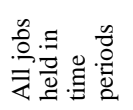

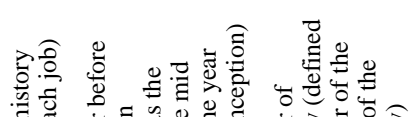

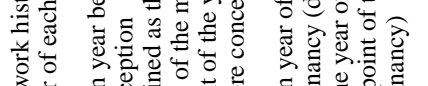

离

政

畜番

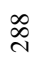

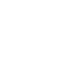

영

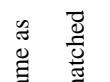

莺

용

当变
势 


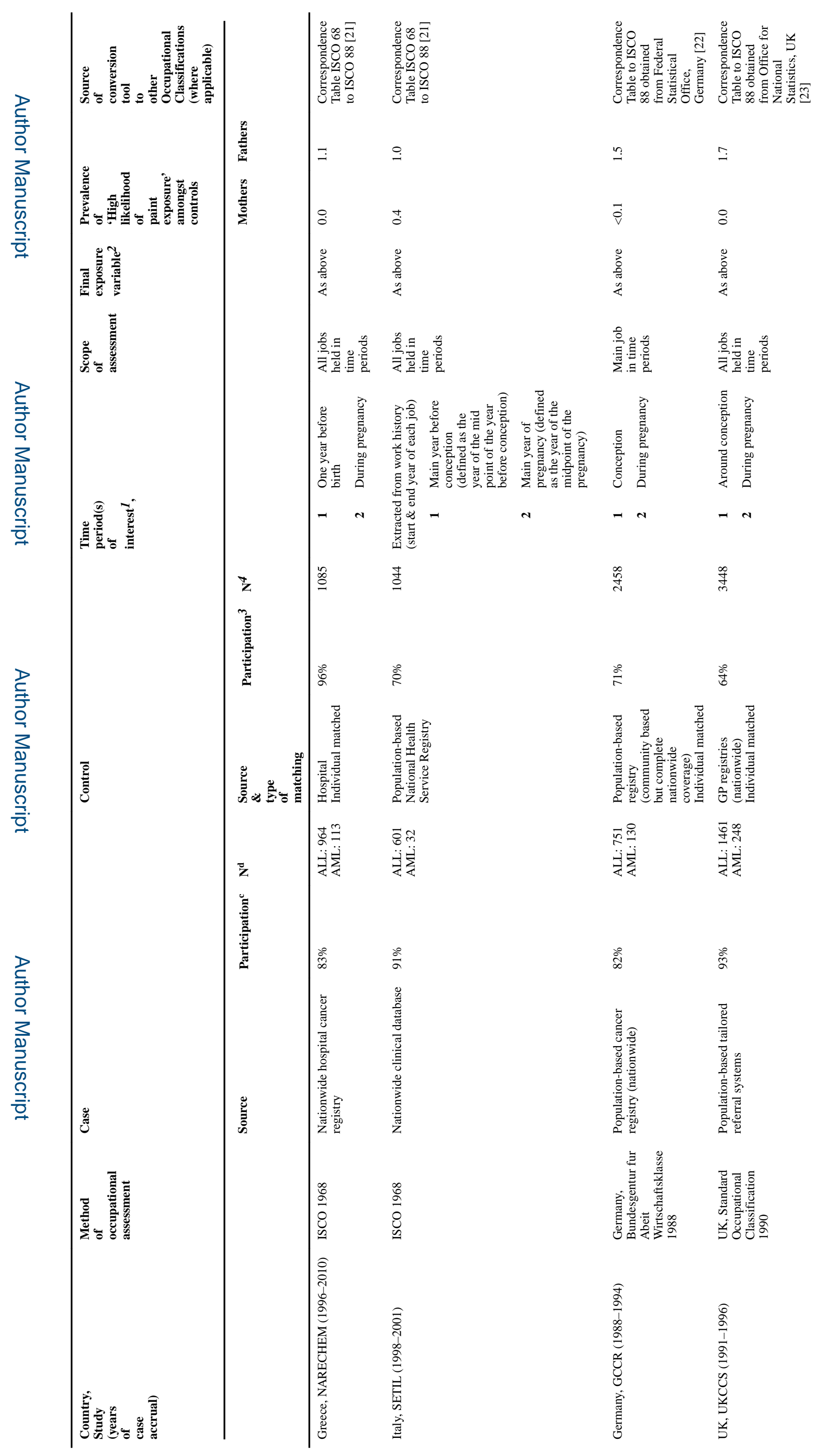




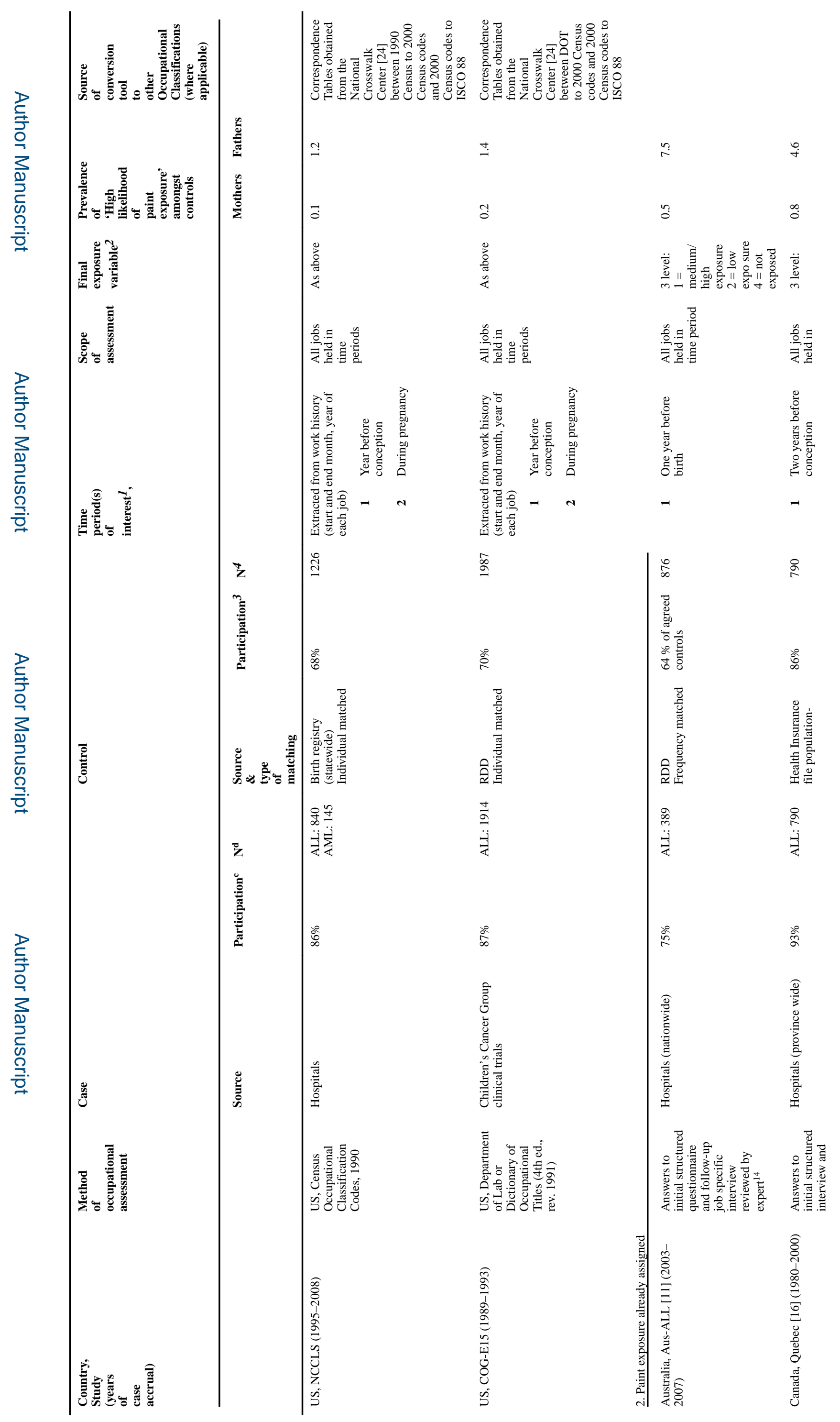




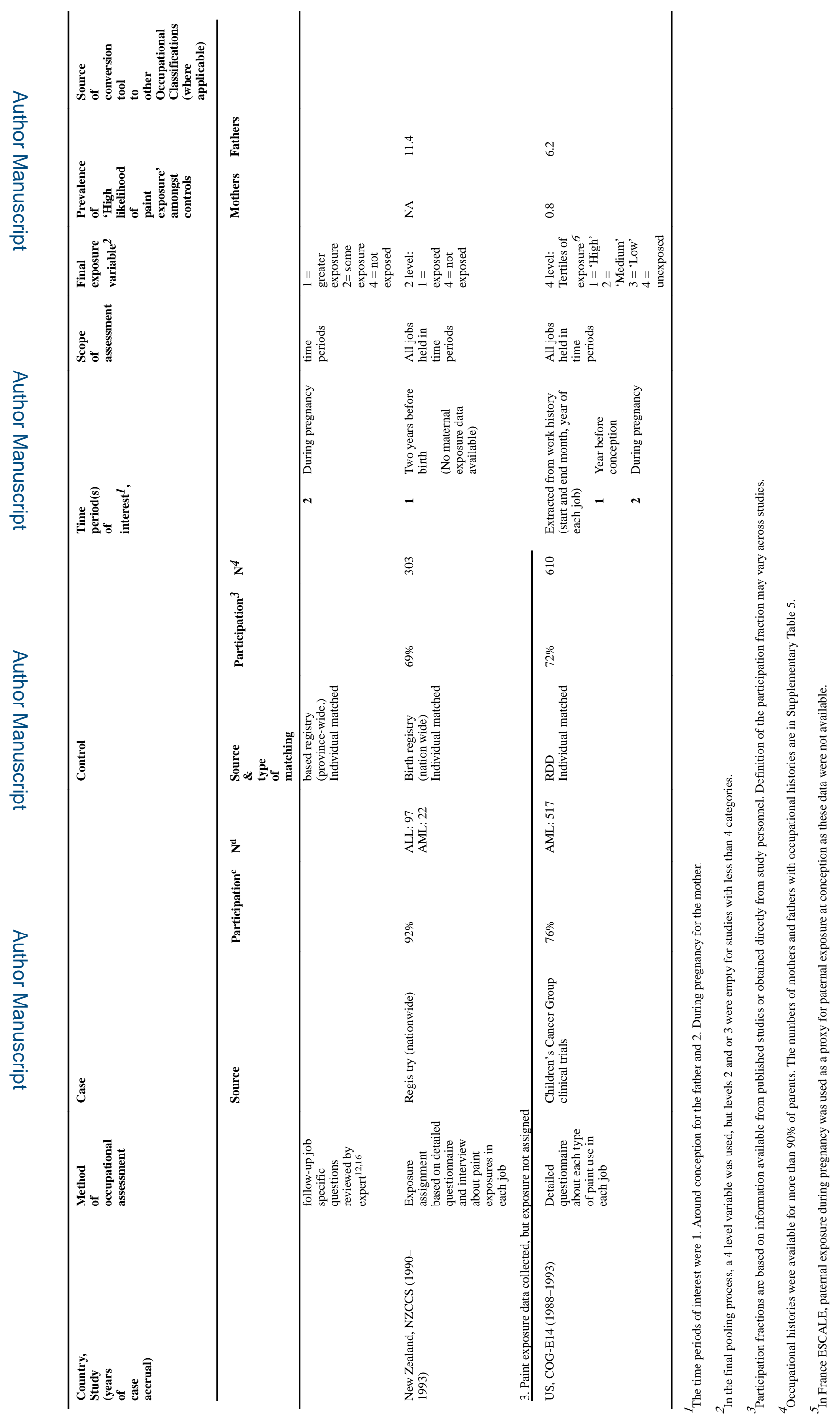




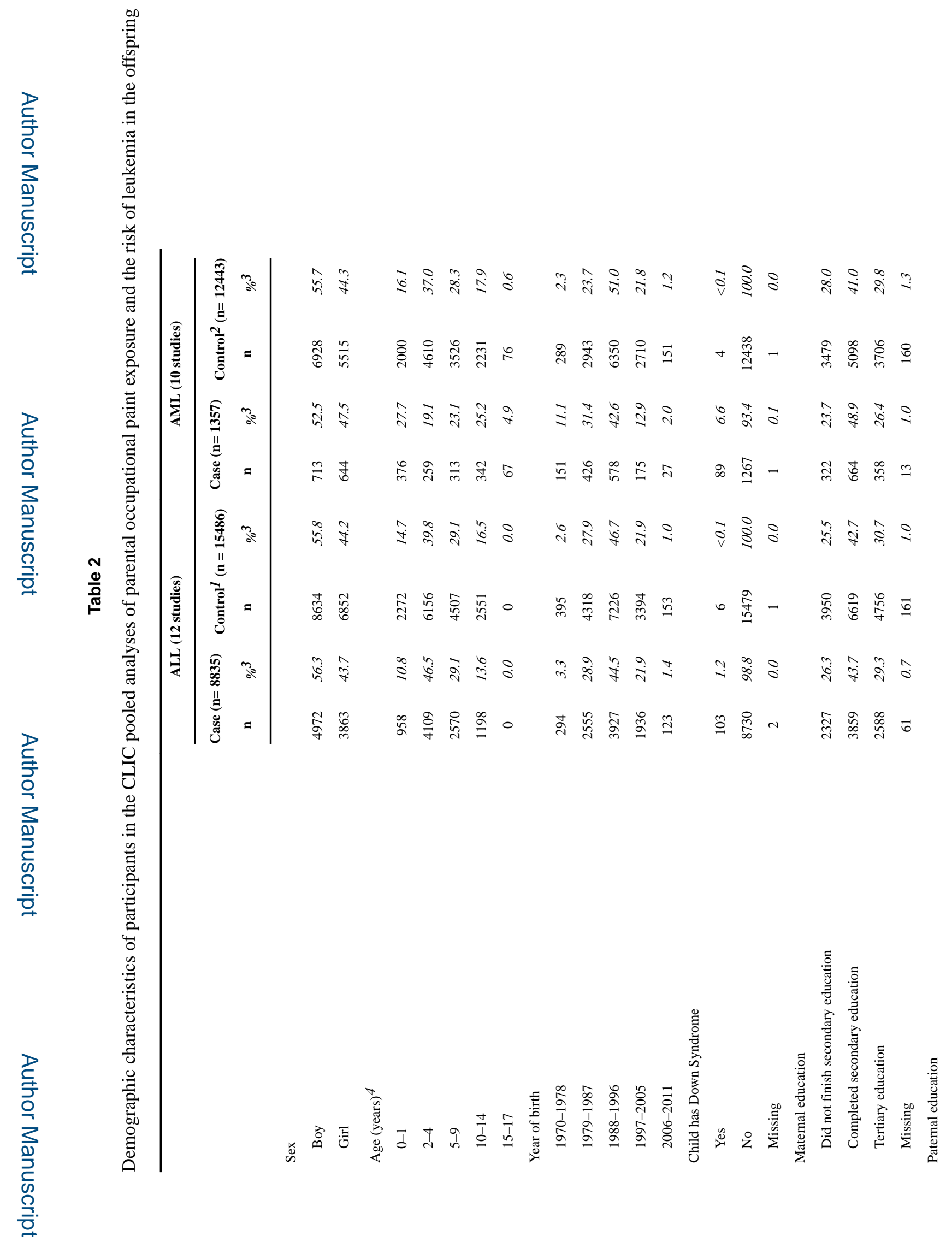

Cancer Causes Control. Author manuscript; available in PMC 2016 April 26. 


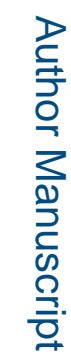

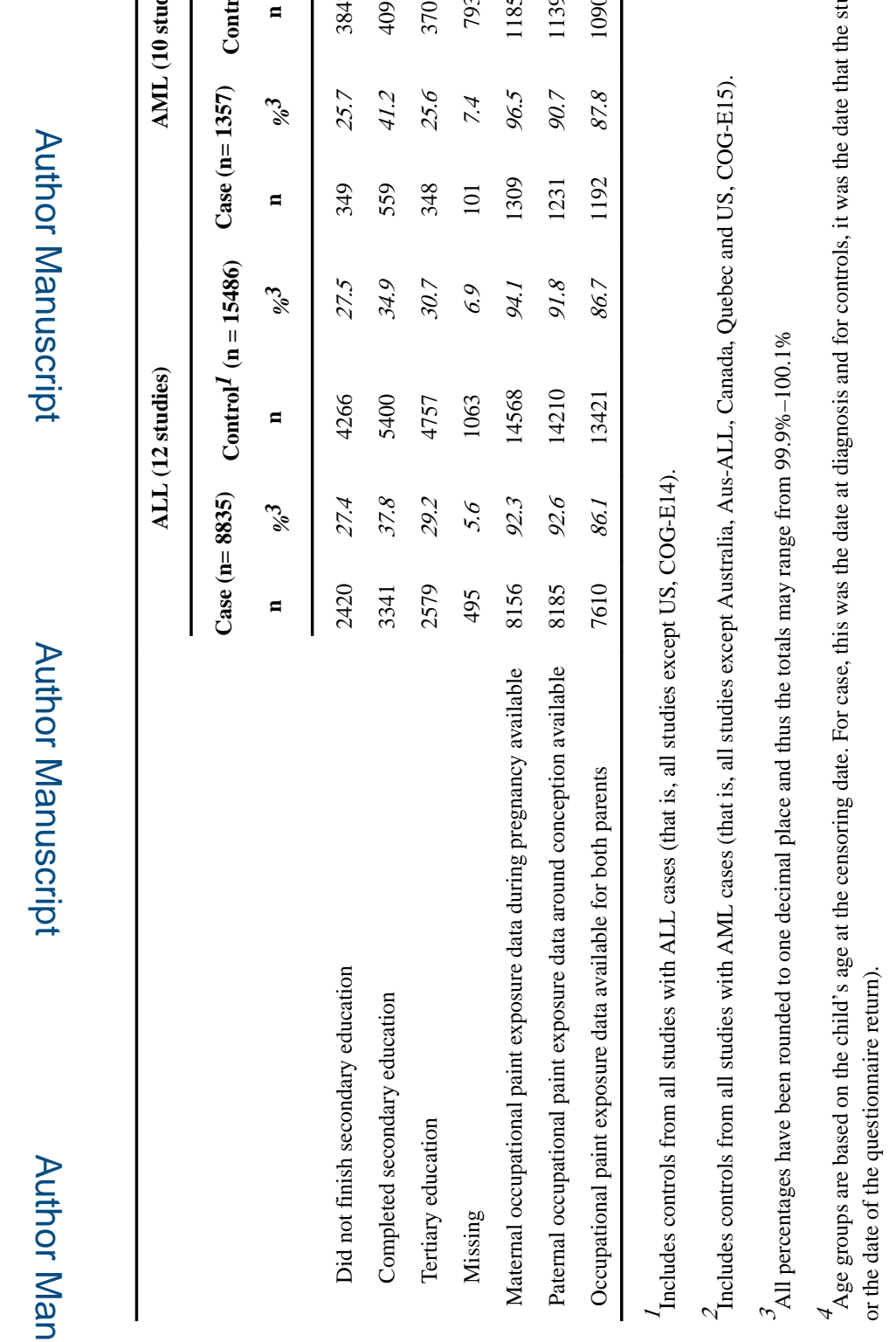

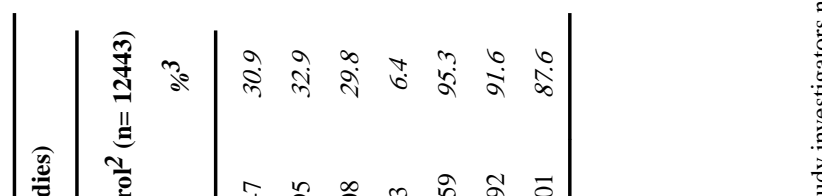

Cancer Causes Control. Author manuscript; available in PMC 2016 April 26. 


\section{Table 3}

Pooled OR (95\% CI) for the association between paternal occupational exposures to paint and the risk of leukaemia in the offspring: Overall and by subgroups

\begin{tabular}{|c|c|c|c|}
\hline & \multicolumn{3}{|c|}{ Paternal exposures around conception } \\
\hline & Total N Case/Controls & $\begin{array}{l}\text { \% in High likelihood of exposure } \\
\text { group }\end{array}$ & $\mathrm{OR}^{1,2},(95 \% \mathrm{CI})$ \\
\hline \multicolumn{4}{|l|}{ 1. ALL } \\
\hline Overall & $8185 / 14210$ & $2.0 / 2.1$ & $0.93(0.76,1.14)$ \\
\hline \multicolumn{4}{|l|}{ Immunophenotype } \\
\hline B-lineage cases & $6457 / 14210$ & $2.1 / 2.1$ & $0.93(0.75,1.15)$ \\
\hline T-lineage cases & $826 / 14210$ & $2.1 / 1.7$ & $0.80(0.46,1.39)$ \\
\hline \multicolumn{4}{|l|}{ Age at diagnosis } \\
\hline Less than 5 years & $4750 / 7826$ & $2.3 / 2.1$ & $1.05(0.81,1.36)$ \\
\hline \multirow[t]{2}{*}{5 or more years } & $3435 / 6384$ & $1.7 / 2.2$ & $0.78(0.56,1.08)$ \\
\hline & & & Interaction $p$ value $=0.45$ \\
\hline \multicolumn{4}{|l|}{ Sex } \\
\hline Girls & $3587 / 6276$ & $2.0 / 2.1$ & $0.97(0.71,1.31)$ \\
\hline \multirow[t]{2}{*}{ Boys } & $4598 / 7934$ & $2.0 / 2.1$ & $0.90(0.69,1.18)$ \\
\hline & & & Interaction $p$ value $=0.12$ \\
\hline \multicolumn{4}{|l|}{ Child's birth year } \\
\hline Before 1996 & $5961 / 10385$ & $2.0 / 2.1$ & $0.88(0.69,1.11)$ \\
\hline \multirow[t]{2}{*}{1996 or later } & $2224 / 3825$ & $2.0 / 2.1$ & $1.08(0.74,1.57)$ \\
\hline & & & Interaction $p$ value $=0.74$ \\
\hline \multicolumn{4}{|l|}{ Type of occupational assessment } \\
\hline Assessment based on expert assessment ${ }^{3}$ & $1114 / 1536$ & $6.2 / 6.0$ & $1.13(0.81,1.58)$ \\
\hline \multirow[t]{2}{*}{ Assessment based on coded job titles ${ }^{4}$} & $6935 / 12384$ & $1.3 / 1.4$ & $0.87(0.67,1.14)$ \\
\hline & & & Interaction $p$ value $=0.29$ \\
\hline \multicolumn{4}{|l|}{ 2. AML } \\
\hline Overall & $1231 / 11392$ & $3.3 / 1.9$ & $0.96(0.65,1.41)$ \\
\hline \multicolumn{4}{|l|}{ Age at diagnosis } \\
\hline Less than 5 years & $584 / 6118$ & $3.3 / 1.8$ & $0.96(0.54,1.73)$ \\
\hline \multirow[t]{2}{*}{5 or more years } & $647 / 5274$ & $3.4 / 2.0$ & $0.90(0.53,1.53)$ \\
\hline & & & Interaction $p$ value $=0.68$ \\
\hline \multicolumn{4}{|l|}{$\operatorname{Sex}$} \\
\hline Girls & $588 / 5034$ & $3.1 / 2.0$ & $0.77(0.43,1.37)$ \\
\hline \multirow[t]{2}{*}{ Boys } & $643 / 6358$ & $3.6 / 1.8$ & $1.17(0.69,1.98)$ \\
\hline & & & Interaction $p$ value $=0.43$ \\
\hline \multicolumn{4}{|l|}{ Child's birth year } \\
\hline Before 1996 & $1008 / 8235$ & $3.8 / 2.2$ & $0.96(0.64,1.44)$ \\
\hline \multirow[t]{2}{*}{1996 or later } & $223 / 3157$ & $1.3 / 1.0$ & $1.21(0.36,4.11)$ \\
\hline & & & Interaction $p$ value $=0.69$ \\
\hline
\end{tabular}

Type of occupational assessment 


\begin{tabular}{|c|c|c|c|}
\hline & \multicolumn{3}{|c|}{ Paternal exposures around conception } \\
\hline & Total N Case/Controls & $\begin{array}{l}\% \text { in High likelihood of exposure } \\
\text { group }\end{array}$ & $\mathrm{OR}^{1,2},(95 \% \mathrm{CI})$ \\
\hline Assessment not based on coded job titles 5 & $482 / 808$ & $6.0 / 8.0$ & $0.96(0.58,1.59)$ \\
\hline \multirow[t]{2}{*}{ Assessment based on coded job titles 6} & $749 / 10584$ & $1.6 / 1.4$ & $0.94(0.52,1.72)$ \\
\hline & & & Interaction $p$ value $=0.46$ \\
\hline \multicolumn{4}{|c|}{ IOR comparing Group 1 (High likelihood of paint exposure) to reference group 4 (No or minimal likelihood of paint exposure) } \\
\hline \multicolumn{4}{|c|}{${ }^{2}$ Adjusted for age, sex, birth year group, study and paternal education } \\
\hline \multicolumn{4}{|l|}{${ }^{3}$ Australia (Aus-ALL), Canada. } \\
\hline \multicolumn{4}{|c|}{$\begin{array}{l}\text { 4France (ADELE \& ESCALE), Greece (NARECHEM 1993-1994 \& 1996-2011), Germany (GCCR), Italy (SETIL), UK (UKCCS), US (COG- } \\
\text { E15) US, NCCLS. See Table } 1 \text { for details of the Occupational coding system. }\end{array}$} \\
\hline \multicolumn{4}{|l|}{ 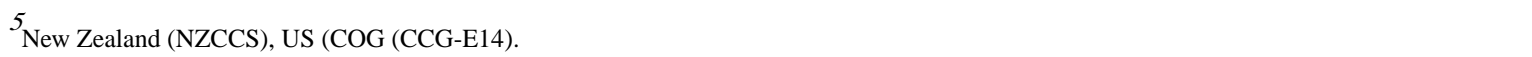 } \\
\hline
\end{tabular}




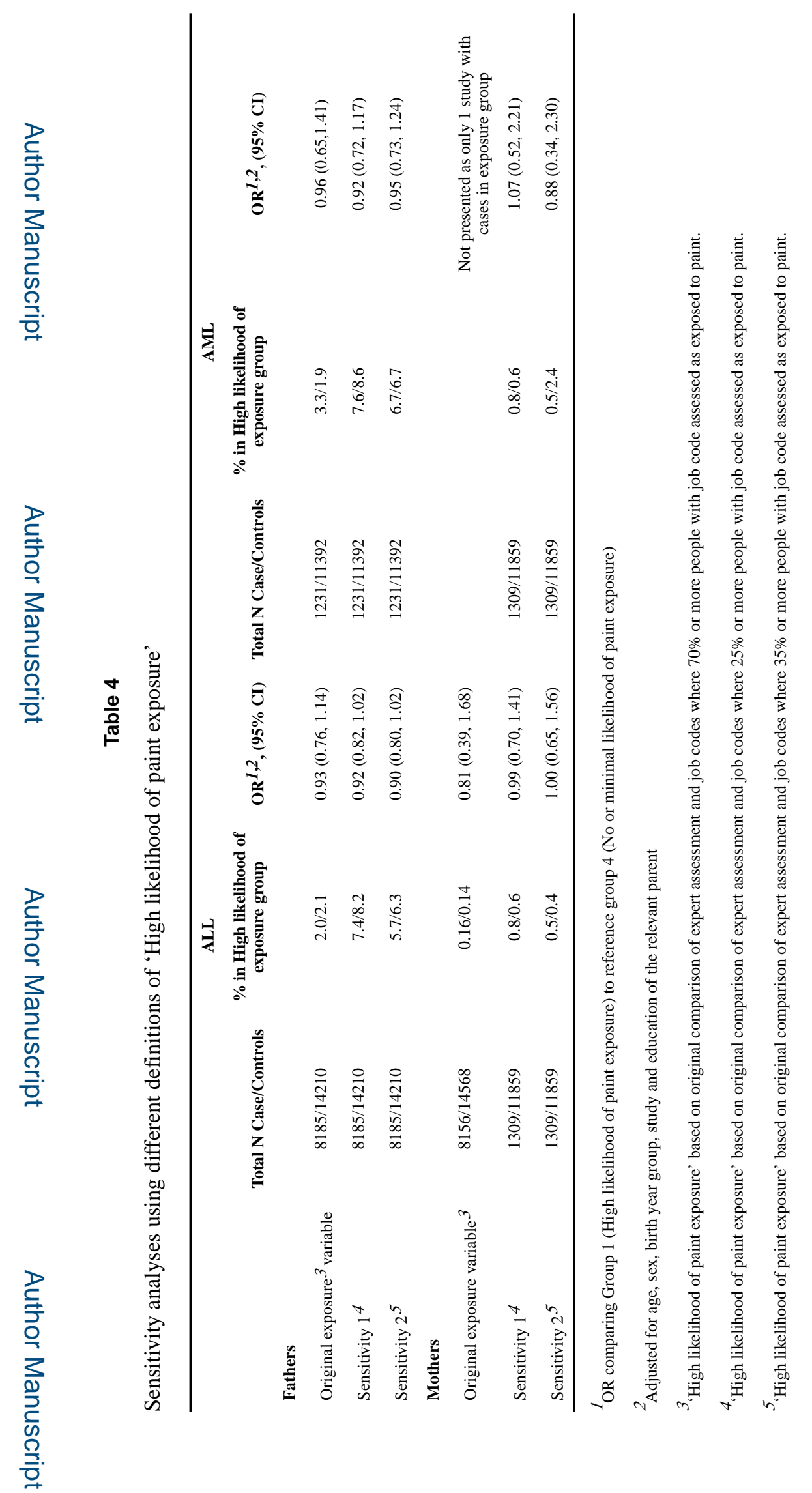

Cancer Causes Control. Author manuscript; available in PMC 2016 April 26. 